
polipropileno. Horticultura Brasileira. 23: 249-254.

\title{
Produção de chicória em função do período de cobertura com tecido de polipropileno
}

\author{
Anderson Luiz Feltrim; Arthur B Cecílio Filho; Bráulio Luciano A Rezende; José Carlos Barbosa \\ UNESP, 14884-900 Jaboticabal-SP; E-mail: andluizfel@yahoo.com.br; rutra@fcav.unesp.br; jcbarbosa@fcav.com.br
}

\section{RESUMO}

O experimento foi realizado na UNESP em Jaboticabal (SP) com o objetivo de avaliar períodos de cobertura de plantas de chicória com polipropileno branco, de $20 \mathrm{~g} \mathrm{~m}^{-2}$, sobre a produção de chicória crespa. O delineamento experimental foi o de blocos casualizados, em esquema fatorial $4 \times 2$, com quatro repetições. Os tratamentos constituíram-se de dois genótipos de chicória (cv. Chicória Crespa, da Isla Sementes, e o genótipo 'AF-218', da Sakata Seeds) e de quatro sistemas de cultivo: (a) ausência de cobertura com polipropileno; (b) cobertura pos 15 dias após o transplantio (DAT); (c) cobertura aos 30 DAT; e (d) 42 DAT coberto, o qual correspondeu a todo o período de crescimento da chicória no campo. A semeadura foi realizada em 02/06/2003 e o transplantio em 27/06/2003. A colocação do polipropileno foi feita diretamente sobre as plantas, fixando-se as laterais na parte externa do canteiro. Na colheita, avaliou-se a altura, número de folhas, diâmetro das plantas, massa fresca e seca da parte aérea. O genótipo 'AF-218' apresentou maior massa fresca da parte aérea que a cv. Chicória Crespa. À medida em que houve aumento do período de cobertura com polipropileno, observou-se aumento na altura, número de folhas e na massa fresca da parte aérea dos dois genótipos. O uso do polipropileno durante todo o ciclo (42 dias) resultou em maior massa seca e promoveu precocidade da colheita em oito dias, além de qualidade superior, com folhas mais tenras e limpas.

Palavras-chave: Cichorium endivia, cultivo protegido, agrotêxtil.

\begin{abstract}
Chicory production affected by different periods of covering with polypropylene

The experiment was carried out in Jaboticabal, São Paulo State, Brazil, to evaluate the production of chicory plants subjected to periods of covering with white polypropylene of $20 \mathrm{~g} \mathrm{~m}^{2}$. The experimental design was a randomized block using a factorial scheme $4 \times 2$, with four replications. The treatments consisted of two chicory genotypes (cv. Chicória Crespa, of Isla Seeds, and 'AF-218', of Sakata Seeds) and four cultivation systems: (a) non covering of the plants with polypropylene; (b) covering 15 days after the transplanting (DAT); (c) covering during 30 DAT; (d) and covering during 42 DAT, corresponding to the entire growth period of chicory in the field. Sowing was done in June $2^{\text {nd }} 2003$ and transplanting in June $27^{\text {th }} 2003$. The placement of the polypropylene was made directly over the plants, fixing the lateral parts in the external side of the plot. At harvest, evaluation was done by measuring plant height and diameter, number of leaves, and shoot fresh and dry mass. After 42 days with polypropylene covering, genotype 'AF-218' showed higher shoot fresh mass ( $439 \mathrm{~g} / \mathrm{plant}$ ) when compared to cv. Chicória Crespa (286 g/plant). Shoot height, number of leaves and shoot fresh mass of the two genotypes increased as the periods of polypropylene covering were longer. The use of polypropylene during the whole plant period of post-transplanting promoted precocity of the crop in eight days, besides superior quality, with more tender and clean leaves.
\end{abstract}

Keywords: Cichorium endivia, row-cover, non-woven.

(Recebido para publicação em 1 de junho de 2005; aceito em 28 de maio de 2006)

\begin{abstract}
$\mathrm{A}$ dversidades climáticas, tais como geada, granizo, excesso de chuva, radiação elevada e baixa temperatura, acarretam perda, quantitativa e qualitativa, na produção de hortaliças, comprometendo a regularidade do fornecimento e, consequentemente, a competitividade e a posição do olericultor no mercado.

Diante deste contexto, a busca por melhor ambiente para o cultivo de hortaliças tem sido o foco principal de muitos pesquisadores. Hoje, são muitas as opções disponíveis no mercado com relação a tipos de estruturas e de materiais que podem ser usados para modificar o ambiente e adequá-lo às necessidades da cultura. Entretanto, todos os materiais (plástico, tela, sombrite, etc.)
\end{abstract}

até hoje usados para ambiente precisam de alguma estrutura ou suporte que impeça o contato destes com a planta, o que representa um investimento, geralmente, de custo elevado.

Uma das alternativas de cultivo protegido que surgiu recentemente é o tecido de polipropileno (TP), também conhecido por agrotêxtil ou tecido não-tecido. Esta técnica consiste na colocação do TP diretamente sobre as plantas ou sobre o solo semeado, dispensando qualquer estrutura de sustentação. A utilização do TP como cultivo protegido vem atender às necessidades das hortaliças folhosas, isso porque para essas culturas a viabilidade econômica em casa de vegetação, e até mesmo sob túneis, é bastante questionada. Os efeitos positi- vos desta técnica são observados na precocidade e aumento da produção de mandioquinha salsa (Reghin et al., 2000), pak choi (Reghin et al., 2001a), morango (Otto et al., 2000a) e salsão (Duda et al., 2000). Além da melhoria da qualidade das plantas de pak choi, observou-se também decréscimo na incidência de doenças (Reghin et al., 2001 b; Colturato et al., 2001) e prolongamento no período de colheita na cultura do pimentão (Pereira et al., 2001).

O uso do tecido de polipropileno iniciou-se na Alemanha em 1971 (Benoit \& Ceustermans 1986), mas não foi aplicado em grande escala até 1978. Wells \& Loy (1985) citam que em 1981 iniciaram-se trabalhos com não-tecido de poliéster, na Universidade de New 
Hampshire, e em 1983 pesquisas com não-tecido de polipropileno. No Brasil, esta técnica tem sido utilizada para a produção de mudas de fumo há algum tempo e os primeiros trabalhos com hortaliças foram avaliados na região sul do país, com a alface (Sá, 1998). Na cultura da alface, além da superioridade na massa fresca, também observou-se melhor qualidade e precocidade das plantas que foram protegidas, qualidade superior e precocidade de 10 dias em alface mini, 8 e 7 dias em alface crespa, respectivamente (Reghin et al., 2001c; Reghin et al., 2002c; Feltrim et al., 2003).

Para as alfaces crespa (cv. Verônica), lisa (cv. Elisa) e americana (cv. Tainá) plantadas no período de inverno, observou-se melhorias na produção qualitativa, quantitativa e precocidade de três dias para a cv. Verônica (Otto et al., 2001). Para a cv. Elisa, o uso desta técnica não se mostrou viável, devido a ocorrência de estiolamento das plantas, e para a cv. Tainá, a cobertura com TP mostrou-se positiva, pois a formação de cabeça ocorreu somente nas plantas que receberam a proteção. Por outro lado, Padilha et al. (2001) observaram uma tendência ao estiolamento, com a formação de cabeça frouxa e impróprias para o mercado em cultivares americanas plantadas no verão. Na cultura do pak choi, Reghin et al. (2002a) observaram aumento de 25 a $75 \%$ na massa, independente da gramatura de TP utilizada (17 e $25 \mathrm{gm}^{-2}$ ).

Já existe um número considerável de trabalhos com TP que proporcionam incrementos na produção e qualidade de hortaliças folhosas. Porém, em função da estação de cultivo, espécie e cultivar avaliada, a presença do tecido de polipropileno por todo o ciclo ou parte dele poderá promover respostas diferenciadas. O objetivo deste trabalho foi avaliar a produção de chicória crespa cultivada sob diferentes períodos de cobertura com polipropileno em comparação à condição tradicional de cultivo, sem cobertura.

\section{MATERIAL E MÉTODOS}

O experimento foi conduzido a campo, na UNESP em Jaboticabal. O solo da área, segundo Oliveira et al. (1999), corresponde ao (LV) Latossolo Vermelho Eutroférrico típico de textura muita argilosa, A moderado caulinítico-oxídico, relevo suave ondulado a ondulado. $\mathrm{O}$ delineamento experimental foi o de blocos casualizados, em esquema fatorial $4 \times 2$, com quatro repetições. Os oito tratamentos constituíram-se da combinação dos fatores genótipos de chicória crespa (cv. Chicória Crespa, da Isla Sementes e o genótipo 'AF-218', da Sakata Seeds) e de quatro sistemas de cultivo: (a) ausência de cobertura com tecido de polipropileno (TP); (b) cobertura com TP aos 15 dias após o transplantio (DAT); (c) cobertura com TP aos 30 DAT; e (d) cobertura com tecido polipropileno por todo o período pós-transplantio. O início do experimento foi em 2 de junho/2003, com a semeadura em bandejas de poliestireno expandido para 128 mudas e substrato Plantmax ${ }^{\circledR}$. As mudas permaneceram em ambiente protegido e foram transplantadas 25 dias após a semeadura, quando apresentavam cinco folhas definitivas, em espaçamento de $0,40 \mathrm{~m}$ entre fileiras e $0,30 \mathrm{~m}$ entre plantas, com 39 plantas por parcela.

A análise química do solo apresentou as seguites características: $\mathrm{pH}$ $\left(\mathrm{CaCl}_{2}\right)$ de 5,$2 ; 25 \mathrm{~g} \mathrm{dm}^{-3}$ de matéria orgânica; $64 \mathrm{mg} \mathrm{dm}^{-3}$ de $\mathrm{P}$ (resina); $\mathrm{K}=$ 3,2 mmol dm $\mathrm{dm}^{-3} \mathrm{Ca}=30 \mathrm{mmol} \mathrm{dm}^{-3}$; $\mathrm{Mg}=13 \mathrm{mmol} \mathrm{dm}^{-3} ; \mathrm{H}+\mathrm{Al}=31 \mathrm{mmol}_{\mathrm{c}}$ $\mathrm{dm}^{-3} ; \mathrm{SB}=46,2 \mathrm{mmol}_{\mathrm{c}} \mathrm{dm}^{-3} ; \mathrm{T}=77,2$ $\mathrm{mmol}_{\mathrm{c}} \mathrm{dm}^{-3} \mathrm{e} \mathrm{V}=60 \%$. Com base na análise de solo, foi realizada a calagem e as adubações de plantio e cobertura seguindo as recomendações de Trani \& Azevedo. (1997). O polipropileno branco com gramatura de $20 \mathrm{~g} \mathrm{~m}^{-2}$ foi colocado sobre as plantas, sendo suas extremidades fixadas com o próprio solo nas laterais do canteiro. Durante a condução do experimento realizou-se duas capinas para as plantas que estavam protegidas com polipropileno e somente uma para as plantas que não receberam a cobertura e irrigações pelo método de aspersão nos períodos de ausência de precipitação com lâminas de aproximadamente $6 \mathrm{~mm}$, diariamente até 15 dias após o transplantio, e posteriormente, com lâminas de aproximadamente 10 $\mathrm{mm}$, a cada dois dias.

A colheita foi realizada aos 42 dias após o transplantio, quando as chicóri- as que tiveram todo o período no campo coberto com TP atingiram o ponto comercial, caracterizado pelo início da senescência das folhas baixeiras. Metade das plantas das parcelas dos outros tratamentos permaneceram no campo por mais oito dias objetivando constatar o tempo adicional para que as plantas atingissem o ponto comercial.

Foram avaliados a altura e o diâmetro das plantas antes da colheita, com auxílio de régua, e o número de folhas e massa fresca e seca da parte aérea. Para obtenção da massa seca, a parte aérea da planta foi lavada e seca à sombra por um dia, sendo posteriormente seca em estufa com circulação forçada de ar, a $65^{\circ} \mathrm{C}$, por 96 h. Além das características da planta, avaliou-se também a temperatura do ar na superfície do solo e a radiação solar com e sem proteção de TP. Para a coleta dos dados, instalou-se sensores de temperatura do ar aos sete dias após o transplantio, conectados ao Datalloger CR 23X - Campbel Scientific, programado para realizar leituras a cada minuto e médias, a cada 1 hora.

Os dados das características da planta foram submetidos à análise de variância, sendo as médias dos genótipos comparadas pelo teste de Tukey a 5\% de probabilidade e as respostas das plantas aos períodos de cobertura, à regressão polinomial.

\section{RESULTADOS E DISCUSSÃO}

As temperaturas máximas e mínimas do ar na superfície do solo com a cobertura com polipropileno foram, respectivamente, maiores e menores do que as observadas em solo sob cultivo sem cobertura com polipropileno (Figura 1A). Em média, os valores das temperaturas máximas e mínimas na superfície do solo das plantas que receberem a cobertura com polipropileno foram, respectivamente, inferiores em $2^{\circ} \mathrm{C}\left(32,7^{\circ} \mathrm{C}-30,7^{\circ} \mathrm{C}\right)$ e superiores em $1,9^{\circ} \mathrm{C}\left(10,6^{\circ} \mathrm{C}-8,7^{\circ} \mathrm{C}\right)$ em relação aos tratamentos sem cobertura. Este resultado é importante principalmente nos dias muito quentes ou nos períodos mais amenos, pois a proteção de polipropileno diminui a temperatura máxima e aumenta a temperatura mínima, proporcionando um microclima mais favorável para o crescimento das plantas. 
Em couve-chinesa, beterraba e espinafre cultivados com proteção de polipropileno também observou-se um regime térmico melhor (Otto, 1997). À medida que as plantas cresceram, as diferenças da temperatura média do ar a $15 \mathrm{~cm}$ do solo, obtidas entre o tratamento com e sem polipropileno, tenderam a diminuir ou até mesmo a inverter, e a intensidade dessas modificações dependeu da época do ano e do crescimento vegetativo da espécie cultivada (Otto, 1997). Uma das razões desses resultados está relacionada, possivelmente, com a formação de uma película de água condensada que se forma no interior do polipropileno, impedindo a emissão da radiação de onda longa para o ambiente externo durante a noite. Segundo Gregoire (1989), a água apresenta transmissividade praticamente nula à radiação longa. Faouzi et al. (1993) observaram que o polipropileno pode elevar a temperatura mínima do ambiente protegido em até $4,3^{\circ} \mathrm{C}$, o que concorda com o aumento na temperatura do ar sob polipropileno de 3 a $5^{\circ} \mathrm{C}$ observado por Otto (1997). Esse comportamento da temperatura do ar em cultivo com polipropileno também foi observado em cultivos com abobrinha (Choukr-allah et al., 1994), couve-chinesa (Hernández et al., 1996) e feijão-vagem (Pereira $e t$ al., 2003). As diferenças entre as temperaturas máximas entre o polipropileno e ambiente natural (sem polipropileno) diminuíram progressivamente com o crescimento das culturas, chegando a inverter-se após a metade dos ciclos.

Neste experimento, embora os valores de temperatura máxima e mínima (Figura 1A) e amplitude térmica (Figura 1B) tenham sido muito próximos nas condições com cobertura e sem cobertura com polipropileno, não foi constatada inversão das características térmicas (temperaturas máxima e mínima e amplitude térmica) próximo a colheita, entre os dois sistemas de cultivo. Provavelmente, a divergência desse resultado com os observados por Choukr-allah et al. (1994), Hernández et al. (1996), Otto (1997) e Pereira et al. (2003) seja a localização do sensor na superfície do solo (e não a $15 \mathrm{~cm}$ de altura), e também a diferença de porte e arquitetura das espécies trabalhadas pelos autores.
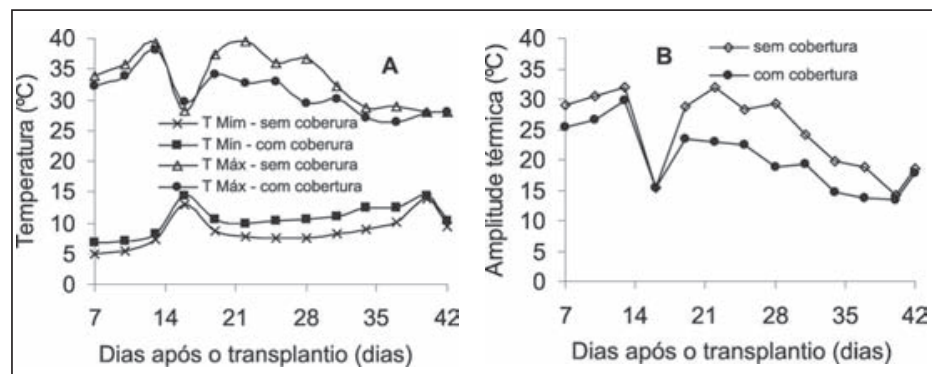

Figura 1. Temperaturas máximas e mínimas (A) e amplitude térmica do ar (B) na superfície do solo com e sem cobertura de polipropileno. Jaboticabal, UNESP, 2003.

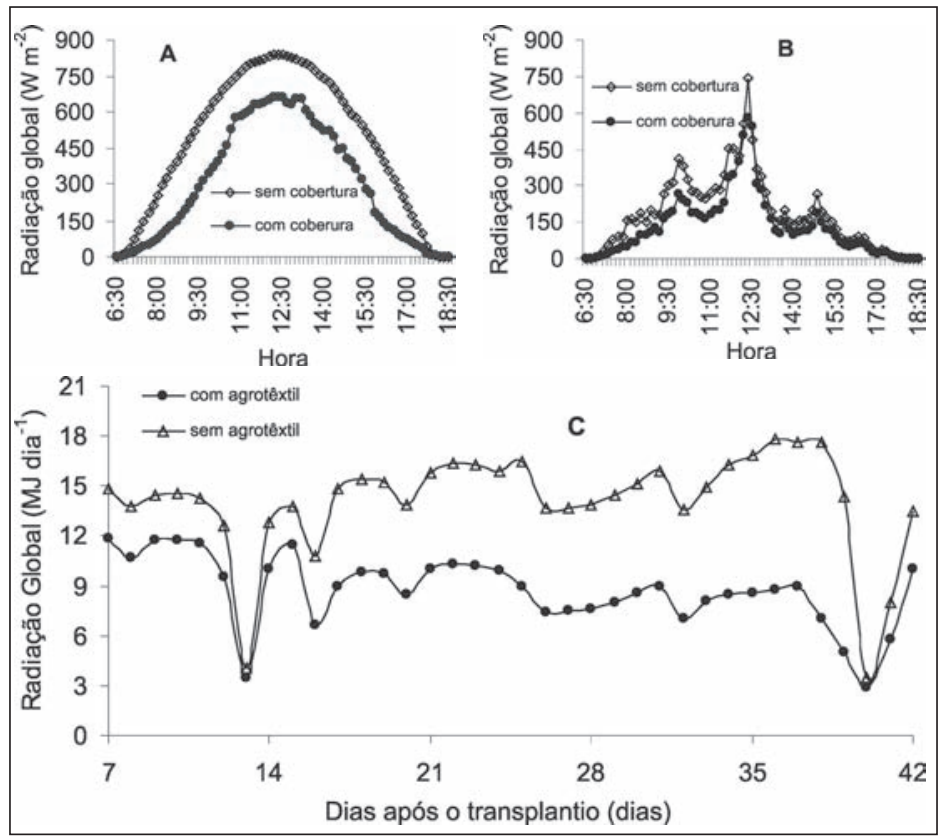

Figura 2. Radiação solar global em dias com ausência de nuvens (A), com presença de nuvens (B) e radiação solar global integral (C) para os cultivos com e sem polipropileno. Jaboticabal, UNESP, 2003.

Com relação à radiação solar global com ausência de nuvens (Figuras $2 \mathrm{~A}$ e 2B), a máxima intensidade de energia foi observada em ausência de nuvens às $12 \mathrm{~h}$ e $20 \mathrm{~min}$ e $12 \mathrm{~h}$ e $30 \mathrm{~min}$, respectivamente, para o ambiente com cobertura $\left(660 \mathrm{~W} \mathrm{~m}^{-2}\right)$ e sem tecido de polipropileno $\left(837 \mathrm{~W} \mathrm{~m}^{-2}\right)$. Relacionando a intensidade máxima de energia com e sem polipropileno obtém-se a transmissividade, que foi de $79 \%$, embora a média de transmissividade do polipropileno para este dia foi de $63 \%$. No dia nublado, também observou-se máxima intensidade de energia de 743 e $578 \mathrm{~W} \mathrm{~m}^{-2}$, ocorridos às $12 \mathrm{~h}$ e $20 \mathrm{~min}$ para o cultivo sem e com polipropileno, respectivamente. Nessa condição a transmissividade foi de $77 \%$ e a média do dia foi de $72 \%$. Segundo Hernandéz \& Morales (1995), a transmissividade do polipropileno fica em torno de $80 \%$ em época de primavera. Nas primeiras horas do dia, devido ao ângulo de incidência dos raios solares e à película de água que se forma na face interna, esta transmissividade atinge valores inferiores (Hernandéz \& Castilla, 1993). Com 

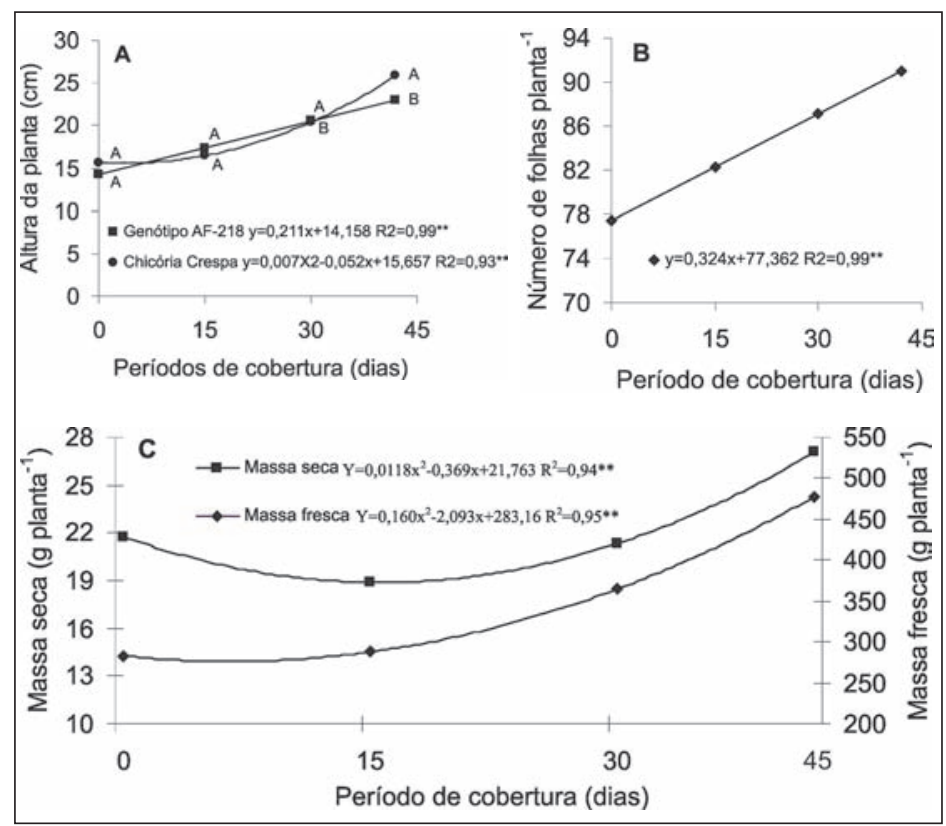

Figura 3. Altura (A), número de folhas (B), massa fresca e seca da parte aérea (C) de plantas de chicória, em função dos genótipos e do período de cobertura da planta com polipropileno em pós-transplantio para o campo. Jaboticabal, UNESP, 2003.

a evolução do dia, a radiação total em um dia ensolarado de primavera é menor sob cobertura do que ao ar livre. Esta redução implica em uma diminuição do ressecamento da superfície do solo, que pode chegar a 20\% (Mermier et al., 1995).

Os valores integrados de radiação com e sem cobertura com polipropileno durante o ciclo da chicória foram de 506,96 e 314,07 $\mathrm{MJ}$ dia $^{-1}$, respectivamente (Figura 2C). A transmissividade até 31 dias após o transplantio variou de 60 a $85 \%$, e no período seguinte, até o final do ciclo, a transmissividade variou de 45 a $60 \%$. O tecido de polipropileno apresentou transmissividade média durante o ciclo da chicória de $61 \%$ da radiação solar incidente. Otto et al. (2000b) observaram variação de 65 a $85 \%$ na transmissividade do polipropileno, variável em função da época do ano e do tempo de uso do material. Em determinados dias, houve diminuição acentuada nos valores de radiação solar no cultivo sem o tecido de polipropileno, fazendo com que se aproximasse dos valores encontrados em cultivo com tecido de polipropileno, sendo a causa dis- to a ocorrência de dias nublados, com grande quantidade de nuvens, fato que diminuiu a radiação para ambos os cultivos. É importante salientar que a radiação é dependente da época do ano, ou seja, da declinação do sol. Em função disto, houve acréscimo da quantidade de radiação com o avanço nos dias julianos no cultivo sem o tecido de polipropileno. O decréscimo de radiação observado no tratamento com cultivo sob TP por todo relacionado ao acúmulo de partículas de solo sobre o TP. Além disso, no final do ciclo houve dias com presença de nuvens, resultando em menor radiação nos dois ambientes de cultivo (Figura 2C).

O melhor desempenho dos genótipos sob cobertura com polipropileno por todo o período pós-transplantio pode ser constatado pelos resultados observados para altura, número de folhas, massa seca e fresca da parte aérea. Somente a altura de plantas foi influenciada significativamente pela interação dos fatores. Número de folhas, massa fresca e seca da parte aérea da chicória foram influenciadas pelo período de cobertura com polipropileno e pelo genótipo, o período pós-transplantio pode estar enquanto o diâmetro de plantas somente pelo fator genótipo. Os dois genótipos de chicória apresentaram comportamento diferente para altura de plantas em resposta ao período de cobertura com polipropileno. A altura das plantas de 'AF-218' aumentou linearmente à medida que aumentou o período de cobertura com polipropileno e a cv. Chicória Crespa respondeu ao mesmo fator de forma quadrática. Embora ambas tenham respondido positivamente à cobertura, não diferiam com até 15 dias de cobertura. Com 30 dias de cobertura, constatou-se maior altura do genótipo 'AF-218' e quando todo o período póstransplantio permaneceu coberto, as plantas da cv. Chicória Crespa apresentaram maior altura (Figura 3A). A altura média de plantas da cv. Chicória Crespa cobertas com polipropileno por todo o período pós-transplantio foi maior em $10,2 \mathrm{~cm}$ em relação às plantas desenvovidas sem cobertura, o que representa um incremento de $65 \%$ na altura de plantas.

O número de folhas aumentou linearmente com o aumento do tempo de cobertura, independente do genótipo, ou seja, o aumento no período de cobertura das plantas com polipropileno proporcionou maior número de folhas para o 'AF-218' e para a cv. Chicória Crespa (Figura 3B). Constatou-se um aumento de aproximadamente 13 folhas por planta, cerca de $17 \%$, quando as plantas ficaram todo o período pós-transplantio cobertas, em relação à ausência de cobertura com polipropileno. A massa seca da parte aérea de plantas de chicória apresentou resposta quadrática ao aumento no período de cobertura de plantas com polipropileno. A massa seca foi de 21,8 g planta $^{-1}$ sem cobertura com polipropileno, sofreu redução para $18,9 \mathrm{~g}$ planta $^{-1}$ aos 15 (DAT) e apresentou 21,3 g planta $^{-1}$ nos primeiros 30 dias após o transplantio. Entretanto, as plantas que permaneceram por todo o período póstransplantio protegidas com polipropileno apresentaram maior massa seca, 27,1 g planta $^{-1}$, cerca de $25 \%$ superior à massa seca de chicória sem cobertura com polipropileno (Figura 3C).

$\mathrm{O}$ uso do polipropileno promoveu efeito semelhante na massa fresca da parte aérea da chicória cv. Chicória 
Crespa e o genótipo 'AF-218'. Maiores massas fresca e seca foram obtidas com o aumento no período de cobertura das plantas com polipropileno. A cobertura de plantas de chicória por todo o período pós-transplantio proporcionou a colheita de plantas com aproximadamente $477 \mathrm{~g}$, cerca de $69 \%$ superior às chicórias crescidas sem a proteção com polipropileno (Figura 3C). O melhor desempenho agronômico do genótipo 'AF-218' e da cv. Chicória Crespa sob cobertura com polipropileno por todo o período pós-transplantio pode ser atribuído ao melhor ambiente, a qual pode ser melhor compreendida pela menor amplitude térmica nesta condição de cultivo (Figura 1B).

Outras hortaliças folhosas também apresentaram aumento na produção mediante o uso polipropileno como tecnologia de ambiente protegido. $\mathrm{Na}$ cultura da alface, Feltrim et al. (2003) e Barros Junior et al. (2004) observaram incremento de $29 \%$ na massa fresca quando as plantas foram protegidas com TP. Sá (1998) também observou aumento na produtividade da cultura da alface quando empregou o polipropileno, entre 26 e $51 \%$, dependendo do grupo a que pertence a alface. Também com alface, Sá (2002) e Reghin et al. (2002b) observaram, respectivamente, aumentos de $29 \%$ a $38 \%$ na produtividade da cultura, quando a cobertura das plantas com polipropileno foi associada à cobertura do solo. Em rucúla, Reghin et al. (2002c) observaram aumento de $20 \%$ na produtividade com o uso do polipropileno a proteção de plantas e incrementos de 25 a $75 \%$ na produtividade de pak choi, dependendo do híbrido.

A cv. Chicória Crespa foi superior ao genótipo 'AF-218' em altura (cerca de $12 \%)$, em número de folhas $(81,2$ e 58,8 folhas/planta, respectivamente) e diâmetro da parte aérea. Entretanto, estes resultados não refletiram em superioridade da cv. Chicória Crespa nas características de massa fresca $(286,1 \mathrm{~g})$ e seca da parte aérea $(20,1 \mathrm{~g})$, muito provavelmente motivado pela diferenças morfológica foliar. O genótipo 'AF-218' apresentou 438,9g de massa fresca e $25,3 \mathrm{~g}$ de massa seca da parte aérea. Enquanto o genótipo 'AF-218' apresenta limbo foliar mais largo desde a região próxima à base do pecíolo, a cv. Chicória Crespa possui limbo mais estreito e repicado, que se alarga a partir de um terço do comprimento foliar, resultando em menor massa seca e fresca da parte aérea. Além do efeito benéfico sobre a altura, número de folhas das plantas, massa seca e fresca da parte aérea, a cobertura da chicória por todo o período pós-transplantio proporcionou colheita oito dias antes que as chicórias cultivadas sem cobertura, 15 e 30 dias após o transplantio.

Em alface, Reghin et al. (2001c) e Otto et al. (2001) também observaram maior precocidade, produção e qualidade das alfaces cobertas com o polipropileno quando comparadas ao cultivo sem polipropileno. Feltrim et al. (2003) observaram que o aumento no período de cobertura das plantas de alface com polipropileno resultou em produto com qualidade superior, maior massa fresca e precocidade de sete dias.

Além da melhoria proporcionada nas características de crescimento e produção da cv. Chicória Crespa e do genótipo 'AF-218' quando as plantas permaneceram por todo o período póstransplantio cobertas com polipropileno, foi constatada também a ótima aparência dessas plantas, que apresentaram folhas grandes tenras e de tonalidade verde-claro. Portanto, recomenda-se o emprego do tecido de polipropileno para cobertura de plantas de chicória, por todo o período pós-transplantio.

\section{AGRADECIMENTOS}

À CAPES pela concessão da bolsa de pesquisa. Às empresas Sakata Seeds e a Isla Sementes S.A., pelo fornecimento das sementes, à Companhia Providência Indústria e Comércio pelo fornecimento do polipropileno e ao Prof. Dr. Jairo Augusto Campos de Araújo pelo empréstimo do Datalloger.

\section{REFERÊNCIAS}

BARROS JÚNIOR AP; GRANGEIRO LC; BEZERRA NETO F; NEGREIROS MZ; SOUZA JO; AZEVEDO PE; MEDEIROS DC. 2004. Cultivo da alface em túneis baixos de agrotêxtil. Horticultura Brasileira 22: 801-803.

BENOIT F; CEUSTERMANS N. 1986. Single and double flat covering of carrots (Daucus carota L.). Acta Horticulturae 176: 41-41.

CHOUKR-ALLAH R; HAFIDI B; REYD G; HAMDY A. 1994. Influence of non-woven on outdoor crops: Moroccan experience. In: INTERNACIONAL CONGRESS OF PLASTIC IN AGRICULTURE, 13. Proceedings... Verona: ICPA. 13p.
COLTURATO AB; JACCOUD FILHO DS; OTTO RF; GASPARINI L. 2001. Avaliação da ocorrência de Alternaria brassicae em couve-chinesa cultivada sob agrotêxtil e em ambiente natural na região de Ponta Grossa - PR. Horticultura Brasileira 19: 291. (Resumo).

DUDA C; REGHIN MY; OTTO RF. 2000. Cultivo do salsão sob proteção com agrotêxtil. In: ENCONTRO DE INICIAÇÃO CIENTÍFICA, 4. Anais... São José dos Campos: Universidade do Vale do Paraíba. p. 43.

FAOUZI EH; CHOUKR RA; HANDI B; REYD G. 1993. Influence of non-wovens on growing winter courgetts in southern Marroco. Plasticulture 98: 31-40.

FELTRIM AL; REGHIN MY; VINNE J. 2003. Cultivo da alface com agrotêxtil em diferentes períodos. Publicatio UEPG 9: 21-27.

GREGOIRE P. 1989. Los no tejidos y la protección de los productos hortícolas. Horticultura 44: 61-64.

HERNÁNDEZ J; CASTILLA N. 1993. El semiforzado con cubiertas flotantes. Hortofruticultura 4: 34-36.

HERNANDEZ J; MORALES MI. 1995. Los agrotextiles y sus aplicaciones. Hortofruticultura 3: 45-47.

HERNANDÉZ J; ROMERO L; CASTILLA N. 1996. Valoración agronómica y análisis microclimático de la técnica de semiproteción de cubiertas flotantes sobre col china. Facultad de Ciencia, Universidad de Granada. 265p.

MERMIER M; REYD G; SIMON JC; BOULARD T. 1995. The microclimate under Agry P17 for growing lettuce. Plasticulture 107: 4-12.

OLIVEIRA JB; CAMARGO MN; ROSSI M; CALDERANO FILHO B. 1999. Mapas pedológicos do Estado de São Paulo: Legenda expandida. Campinas: EMBRAPA Solos. 63p.

OTTO RF. 1997. Cubiertas de agrotextil en especies hortícolas: balances térmicos, evapotranspiración y respuestas productivas. Tesis Doctoral. Universidad de Córdoba, Escuela Técnica Superior de Ingenieros Agrónomos y Montes. Córdoba: España. 157p.

OTTO RF; REGHIN MY; TIMÓTEO P; PEREIRA AV; MADUREIRA A. 2000a. Resposta produtiva de duas cultivares de morango cultivadas sob "não tecido" de polipropileno no município de Ponta Grossa - PR. Horticultura Brasileira 18: 210-21. (suplemento).

OTTO RF; GIMENEZ C; CASTILIA N. 2000b. Modificações microclimáticas sob proteção de polipropileno cultivado com espécies hortícolas em Córdoba, Espanha. Horticultura Brasileira 18: 204-211.

OTTO RF; REGHIN MY; SÁ GD. 2001. Utilização do "não tecido" de polipropileno como proteção da cultura da alface durante o inverno de Ponta Grossa - PR. Horticultura Brasileira 19: 49-52.

PADILHA JM; TUPICH FLB; REGHIN MY. 2001. Cultivo protegido de alface americana. IV. Estação de verão. In: ENCONTRO DE INICIAÇÃO CIENTÍFICA, 10. Anais... Ponta Grossa-PR: UEPG. p. 169.

PEREIRA AV; OTTO RF; REGHIN MY. 2001. Efeito da proteção com não tecido na produtividade da cultura do pimentão em Ponta Grossa - PR. Horticultura Brasileira 19: suplemento CD-ROM. 
PEREIRA AV; OTTO RF; REGHIN MY. 2003. Respostas do feijão-vagem cultivado sob proteção com agrotêxtil em duas densidades de plantas. Horticultura Brasileira 21: 564-569.

REGHIN, MY; OTTO RF; SILVA JBC. 2000 "Stimulate Mo" e proteção com 'não tecido" no pré-enraizamento de mudas de mandioquinha-salsa. Horticultura Brasileira 18: 53-57.

REGHIN MY; OTTO RF; DALLA PRIA M; FELTRIN AL; VINNE J. 2001a. Cobertura do solo e proteção das plantas de pak choi cultivadas com "'não tecido" de polipropileno no período da primavera. Horticultura Brasileira 19: suplemento CD-ROM.

REGHIN MY; PRIA MD; FELTRIN AL; DER VINNE JV. 2001b. Efeito da cobertura do solo e proteção das plantas de pak choi cultivadas com "não tecido" de polipropileno na ocorrência de doenças. Horticultura Brasileira 19: suplemento CD-ROM.
REGHIN MY; OTTO RF; DUDA C; PADILHA JM; TUPICH FLB. 2001c. Produção de alface com cobertura do solo e proteção da plantas com "não tecido" de polipropileno. Horticultura Brasileira 19: suplemento CDROM.

REGHIN MY; OTTO RF; VINNE J; FELTRIM AL. 2002a. Produção de repolho branco chinês (pak choi) sob proteção com 'não tecido" de polipropileno. Horticultura Brasileira 20: 233-236.

REGHIN MY; DALLA PRIA M; OTTO RF; FELTRIM AL; VINNE J. 2002b. Sistemas de cultivo com diferentes espaçamentos entre plantas em alface mini. Horticultura Brasileira 20: suplemento CD-ROM.

REGHIN MY; OTTO RF; PRIA MD; FELTRIM AL; VAN DER VINNE J. 2002c. Uso da cobertura de solo e da proteção das plantas na produção de rúcula. Horticultura Brasileira 20: Suplemento 2 .
SÁ GD. 1998. Efeito da proteção com "'não tecido" sobre o desenvolvimento e produção da alface (Lactuca sativa L.). 31p. Ponta Grossa: UEPG. (Monografia de conclusão de curso.

SÁ GD. 2002. Efeitos da cobertura de solo e da proteção das plantas na cultura da alface. 30 Ponta Grossa: UEPG. (Monografia especialização.

TRANI PE, AZEVEDO FILHO JA. 1997. Alface, almeirão, chicória, escarola, rúcula e agrião d'água. In: RAIJ B; CANTARELLA H; QUAGGIO JA; FURLANI AMC. Recomendação de adubação e calagem para o Estado de São Paulo. Campinas: IAC. p. 168. (Boletim técnico, 100).

WELLS OS; LOY JB. 1985. Intensive vegetable production with row covers. HortScience 20: 822-826. 